[15] Van Dijken, J. W. V., Pallesen, U. (2011). Clinical performance of a hybrid resin composite with and without an intermediate layer of flowable resin composite: A 7-year evaluation. Dental Materials, 27 (2), 150-156. doi: http://doi.org/10.1016/j.dental.2010.09.010

[16] Shashmurina, V. R., Kupreeva, I. V., Devlikanova, L. I., Gusenov, R. K., Gaidukov, G. A. (2018). Klinicheskii opyt primeneniia universalnogo restavratsionnogo kompozita svetovogo otverzhdeniia "Restavrin" (OOO "TekhnoDent", Rossiia) dlia vosstanovleniia zhevatelnoi gruppy depulpirovannykh zubov. Vestnik Smolenskoi gosudarstvennoi meditsinskoi akademii, 17 (3), 193-197.

[17] Dzhuraeva, Sh. F., Vorobev, M. V., Tropina, A. A. (2018). Obosnovanie effektivnosti vosstanovitelnoi terapii zubov posle endodonticheskogo lecheniia. Sovremennye problemy nauki i obrazovaniia, 4, 55-59.

[18] Azizov, A. N. (2019). Sovershenstvovanie metodov priamoi restavratsii zubov bokovoi gruppy pri ispolzovanii stekloionomernykh tsementov i kompozitsionnykh materialov. Samara, 24.

\title{
CHANGES IN THE MORPHOLOGIC STATE OF RED BLOOD CELLS IN PATIENTS WITH POLYTRAUMA
}

\author{
Mariia Matvieienko ${ }^{1}$ \\ mariia.matvieienko@karazin.ua \\ Alena Gryshchenko ${ }^{1}$ \\ Nadiia Baranova ${ }^{2}$ \\ Arora Sukesh \\ Ievgen Bausov ${ }^{2}$ \\ ${ }^{1}$ Department of Surgical Diseases, Operative Surgery and Topographical Anatomy \\ V. N. Karazin Kharkiv National University \\ 4 Svobody sq., Kharkiv, Ukraine, 61022 \\ ${ }^{2}$ Department of Emergency medicine, Anesthesiology and Intensive Care \\ Kharkiv National Medical University \\ 4 Nauky ave., Kharkiv, Ukraine, 61022
}

\footnotetext{
Abstract

The measurement of RBC indices is of particular importance as an indirect intermediate component of the recovery process after exposure to hypoxia, ischemia, hypothermia in patients with traumatic disease due to polytrauma.

The aim of this study was to evaluate the parameters of the morphologic state of red blood cells as a reaction of patients with traumatic disease.

Materials and methods. A prospective study was carried out evaluation of 120 patients suffering from polytrauma. The patients were divided into 3 groups according to the principle of using additional substances as a part of IC. The parameters of morphologic state of red blood cells were studied.

Results. The course of acute and early periods of traumatic disease has accompanied variability morphological forms of red blood cells, as evidenced by a decrease in MCV and RDW increased levels of the 3rd to 5th day. The optimized therapy used in the treatment of patients, has a positive effect on the parameters of red blood cells, contributes to a better recovery of red blood cells after hypoxia resulting multiple trauma.

Conclusion. The study has demonstrated variations in the morphologic properties of red blood cells in the acute and early period of traumatic disease, as confirmed by pathological changes of the erythrocyte indices. The administration of the proposed
} 
therapy with the use of D-fructose-1.6-diphosphate sodium salt of hydrate has a positive effect on the parameters of red blood cells, contributes to a better recovery after hypoxia resulting multiple trauma. Given this, the calculations of the red blood cell indices may carry additional diagnostic information, which allows identify trends for not obvious pathological changes and quality of treatment.

Keywords: traumatic disease, red blood cells indices, D-fructose-1.6-diphosphate sodium hydrate.

DOI: $10.21303 / 2504-5679.2020 .001373$

\section{Introduction}

The massive bleeding, violation of microreological properties of the blood, hypoperfusion are key factors in the pathogenesis of traumatic diseases. These pathological changes lead to a decrease in the availability of oxygen to the tissues, disturbances in the hemostasis system, stimulation of the inflammatory response, which ultimately leads to the development of hypoxia [1, 2]. The probability of septic complications, multiple organ failure and mortality depends on its duration and severity $[2,3]$.

Red blood cells (RBC) are the most important cells that, on the one hand, perform the oxygen transport, and on the other hand, they are subject to changes when exposed to hypoxia [4-6]. The RBC's structure is optimal for its main function: efficient oxygen delivery and $\mathrm{CO}_{2}$ removal. It lacks organelles and a nucleus, thereby providing more space for the oxygen-carrying protein hemoglobin. Furthermore, its typical biconcave, flexible shape does not only maximize the surface/ volume ratio for gas exchange, but also makes it capable of withstanding the mechanical stress it experiences during the many times it travels the circulatory system. Often, RBCs have been oversimplified as a 'bag of hemoglobin', while in reality they are much more complex. Their membrane-cytoskeleton build-up enables the cell to resist fragmentation while undergoing extensive deformation in the microcapillaries and the spleen. Furthermore, RBCs contain important enzymes and substrates for several metabolic pathways and antioxidant defense mechanisms [7].

Blood viscosity is determined by red blood cells flow properties that include adhesion, aggregation and deformability, i. e., ability to change shape under a given stress without hemolysis. Erythrocyte deformability affects blood flow in large blood vessels, due to the increased frictional resistance between fluid layers under laminar flow conditions. It also affects the microcirculatory blood flow significantly where erythrocytes are forced to pass through blood vessels with diameters smaller than their size. Numerous pathologies are associated with a decrease of RBC deformability [8-10].

Progressing changes in RBC shapes are accompanied by impairment of the cytoskeleton and plasma membrane, decreased intracellular adenosine triphosphate (ATP) concentration, as well as changes in the functional characteristics of RBC: reduced transport function and increased membrane deformability [4].

Recent literature supports the notion that the condition of the membrane and the ability of erythrocytes to deform largely depend on the intracellular content of ATP.If ATP level will decrease, the deformity decreases and if it will increase, the deformity increases [10, 11]. The glycolysis is the single source of ATP in erythrocytes. Energy is important for ensuring the integrity of the membrane and the biconcave shape of erythrocytes, the ability to perform oxygen transport function and energy production for ion pumps [12, 13]. Oxidation of glucose in the erythrocyte has two goals: energy and antioxidant. Inhibition of glycolysis leads to a violation of these functions and, accordingly, hemolysis. When the level of ATP falls below $10 \%$ of the normal value the erythrocytes lose potassium ions, their spherulation occurs and eventually undergo osmotic lysis [9, 11, 13].

Today, many different erythrocyte indices are important diagnostic indicators. These parameters characterize morphological characteristics and allow to estimate the size of RBCs and hemoglobin content in them. The deviations from normal values of these indicators point the nature of anemia and the function of forming hemoglobin in RBCs [9-11].

Thus, the measurement of RBC indices is of particular importance as an indirect intermediate component of the recovery process after exposure to hypoxia, ischemia, hypothermia in patients with traumatic disease due to polytrauma. 
The aim of this study was to evaluate the parameters of the morphologic state of RBCs as a reaction of patients with traumatic disease (TD). In case, they were operated according to multistage surgical correction strategy and use different variants of intensive care (IC).

\section{Materials and methods}

The study was conducted in anesthesiology and intensive care unit for patients with combined trauma on the basis of prof. A. I. Meshchaninov Kharkiv City Clinical Hospital of Emergency Medicine. We carried out evaluation of 120 patients suffering from polytrauma in the period from 2015 to 2017.

All studies were conducted in accordance with the Council of Europe Convention on the Protection of Human Rights and Human Dignity in Connection with the Application of Biology and Medicine: Convention on Human Rights and Biomedicine (ETS No. 164) of 04.04.1997, and the Helsinki Declaration of World Health Association (2008). All of patients or their legal representatives signed an informed consent to participate in the study, and all measures were taken to ensure patient anonymity (the ethics committee of V. N. Karazin Kharkiv National University School of Medicine, protocol No. 3, from 11.03.2020)

The conditions for including patients into the study were multiple trauma, ISS $>15$ points, class III-IV blood loss according to the classification of the American College of Surgeons, body temperature $34-36{ }^{\circ} \mathrm{C}$, age 18 to 60 years (average age $37.9 \pm 12.8$ years), absence of severe traumatic brain injury.

The patients were divided into 3 groups according to the principle of using additional substances as a part of IC. The Control group consisted of 32 patients and had not composed additional substances destination for intensive care. 32 patients were included in CP group, and in addition to the IC algorithm Ceruloplasmin $(5 \mathrm{mg} / \mathrm{kg} 1$ time per day intravenously at a rate of 30 drops per minute for 10 days) was prescribed. FDP group included 56 patients who additionally the intensive care algorithm was assigned a solution of D-fructose-1.6-diphosphate sodium hydrate $(150 \mathrm{mg} / \mathrm{kg}$ per day administered intravenously at a rate of $10 \mathrm{ml}$ per minute over 10 days from the time of admission to the operating room).

All of patients were comparable by severity of trauma and condition at the time of admission.

To achieve this goal, we conducted a study of the parameters of morphologic state of erythrocytes. Actually, an important diagnostic indicators are some RBC indices. Mean Cell Volume (MCV), Mean cell hemoglobin ( $\mathrm{MCH})$, Mean cell hemoglobin concentration (MCHC), Red cell distribution of width (RDW) were analyzed in patients all of groups. The erythrocyte morphofunctional state parameters were determined on a hematology analyzer ABX Micros 60 by HORIBA ABX Diagnostics (France).

The following control points were used: at the time of admission, 24 hours later, on the 3rd, 5 th and 14th days of intensive care during the strategy of multi-stage surgery. Statistical processing of the obtained results was performed using the software «Microsoft Office 2010», «Microsoft Excel 2010». Statistical analysis was done using the Student's t-test.

\section{Results}

Statistical analysis has revealed that the MCV was within normal range in patients groups $\mathrm{C}$, $\mathrm{CP}$ and FDP, and averaged $88.4 \pm 3.9 \mathrm{mkm}$. The dynamic of MCV figures are presented in Table 1.

Too large a size of RBCs will cause difficulty in the passage of blood cells through the smallest capillaries, a small size will lead to insufficient hemoglobin inside. In both cases, the risk of hypoxia increases - oxygen starvation with corresponding consequences for the whole body [7].

Thus, in the control group, whose patients were given IC according to the local protocol, without additional means to counteract hypoxia, after 24 hours, the MCV was $74.2 \pm 3.6 \mu \mathrm{m}^{3}$, that is $16 \%$ likely $(\mathrm{p}<0.05)$ lower for the starting level $\left(\mathrm{MCV}_{\text {start }}\right)$. In groups $\mathrm{CP}$ and FDP, after 24 hours, $\mathrm{MCV}$ was reduced to $78.1 \pm 3.8 \mu \mathrm{m}^{3}$ and $83.2 \pm 4.3 \mu \mathrm{m}^{3}$, which is $11.7 \%$ and $5.9 \%$ lower than the starting value. On the 3 rd day of hospital stay, there was a relative decrease in MCV in all studied patients. In the Control and CP groups it were by $15.8 \%$ and $14.5 \%$ significantly $(\mathrm{p}<0.05)$ lower than the starting level, while in group FDP by $4.3 \%$, which is likely no different from the $\mathrm{MCV}_{\text {start }}$ 
Table 1

The dynamic of morphometric and functional properties of red blood cells, $\mathrm{M} \pm \mathrm{m}$

\begin{tabular}{|c|c|c|c|c|c|}
\hline Group & At admission & After 24 hours & On 3 day & On 5 day & On 14 day \\
\hline \multicolumn{6}{|c|}{$\mathrm{MCV}, \mu \mathrm{m}^{3}\left(88.4 \pm 3.9-\mathrm{MCV}_{\text {start }}\right)$} \\
\hline Control & $88.6 \pm 3.9$ & $74.2 \pm 3.6^{*}$ & $74.4 \pm 2.8^{*}$ & $75.1 \pm 4.4^{*}$ & $80.6 \pm 5.4$ \\
\hline $\mathrm{CP}$ & $88.4 \pm 3.6$ & $78.1 \pm 3.8^{*}$ & $75.6 \pm 5.8^{*}$ & $79.8 \pm 5.4$ & $82.8 \pm 5.1$ \\
\hline FDP & $88.2 \pm 4.2$ & $83.2 \pm 4.3$ & $84.6 \pm 4.1$ & $86.6 \pm 5.2$ & $88.4 \pm 4.3$ \\
\hline \multicolumn{6}{|c|}{ MCH, pg (30.1 $\left.\pm 1.4-\mathrm{MCH}_{\text {start }}\right)$} \\
\hline Control & $31.2 \pm 1.3$ & $25.9 \pm 1.6^{*}$ & $25.4 \pm 2.2 *$ & $27.1 \pm 1.2$ & $28.6 \pm 1.1$ \\
\hline $\mathrm{CP}$ & $29.8 \pm 1.6$ & $26.4 \pm 1.3^{*}$ & $25.7 \pm 2.8$ & $28.2 \pm 1.2$ & $30.8 \pm 2.2$ \\
\hline FDP & $28.9 \pm 1.2$ & $28.1 \pm 1.6$ & $27.4 \pm 2.3$ & $28.6 \pm 1.3$ & $31.4 \pm 1.8$ \\
\hline \multicolumn{6}{|c|}{ MCHC, g/l (327 $\pm 17-$ MCHC $\left._{\text {start }}\right)$} \\
\hline Control & $319 \pm 18$ & $296 \pm 18$ & $298 \pm 24$ & $302 \pm 18$ & $302 \pm 14$ \\
\hline $\mathrm{CP}$ & $324 \pm 14$ & $303 \pm 22$ & $302 \pm 20$ & $308 \pm 18$ & $314 \pm 16$ \\
\hline FDP & $339 \pm 16$ & $30825 \pm$ & $306 \pm 18$ & $312 \pm 15$ & $325 \pm 12$ \\
\hline \multicolumn{6}{|c|}{ RDW, \% (13.1 $\pm 0.9 \%-$ RDW $\left._{\text {start }}\right)$} \\
\hline Control & $13.4 \pm 1.2$ & $17.6 \pm 1.8^{*}$ & $16.2 \pm 1.3^{*}$ & $14.7 \pm 1.2$ & $13.8 \pm 1.1$ \\
\hline $\mathrm{CP}$ & $13.2 \pm 1.2$ & $16.7 \pm 1.5^{*}$ & $15.1 \pm 1.3$ & $14.0 \pm 0.8$ & $13.4 \pm 0.9$ \\
\hline FDP & $12.8 \pm 0.9$ & $14.7 \pm 1.2$ & $14.1 \pm 1.1$ & $12.9 \pm 0.7$ & $12.8 \pm 1.1$ \\
\hline
\end{tabular}

Note: * - significance of differences in the Student's t-test relative to baseline $p<0.05$

MCV relative decline may be due to high content of fragments of red blood cells (acute traumatic coagulopathy, mechanical hemolysisetc) [6, 14]. Further, on the 5th day, the index of mean cell volume has slightly increased in all of groups and amounted to $75.1 \pm 4.4 \mu \mathrm{m}^{3}, 79.8 \pm 5.4 \mu \mathrm{m}^{3}$, $86.6 \pm 5.2 \mu \mathrm{m}^{3}$ in Control, CP and FDP groups, i. e. $15 \%, 9.7 \%$ and $2 \%$ below $\mathrm{MCV}_{\text {start }}$, respectively. On day 14, the upward trend has continued MCV and did not differ significantly from baseline in all of groups.

\section{Discussion}

This shows the unconditional benefit of prescribing additional compounds that affects the metabolism of oxygen in the body. In addition, despite the similar dynamics of recovery of MCV numbers in the blood of patients in groups CP and FDP, their maximum deviations from baseline were observed in group CP. In our oppinion, this is due to the increased content of fragments of RBCs in the blood, as a result of acute traumatic coagulopathy. Therefore, the additional appointment of D-fructose-1.6-diphosphate sodium salt of the hydrate has a positive effect on the functional state of RBCs.

Also, the analysis of the data indicators of $\mathrm{MCH}$ have shown no significant difference in the control points in patients of control, CP and FDP groups and demonstrated the following dynamics (Table 1). 24 hours after the start of the IC index of MCH has decreased by $14 \%, 12.3 \%$ and $6.6 \%$, on the 3rd day - by $15.6 \%, 14.6 \%$ and $9 \%$ relative to starting level $\left(\mathrm{MCH}_{\text {start }}\right)$, respectively in patients of control, CP and FDP groups. From the 5th to the 14th day, this indicator had a tendency to recovery and was authentically no different from starting level in all of groups.

Thus, it could be noted that, in general, on the 3rd day of treatment, were observed significant $(\mathrm{p}<0.05)$ and maximum deviations $\mathrm{MCH}$ from $\mathrm{MCH}_{\text {start }}$ in Control and FDP groups. It was despite the similar dynamic of $\mathrm{MCH}$ numbers in the blood for all investigated groups. The obtained data have evidenced of the unconditional benefit of prescribing D-fructose-1.6-diphosphate sodium salt hydrate. This is due to the affect the metabolism of oxygen in the body, which is likely pathogenetically significant in the restoration of $\mathrm{MCH}$.

The study has not revealed significant differences between the groups of the mean cell hemoglobin concentration in the RBCs. Control, CP and FDP groups have shown reduction of MCHC 
indices relative to starting level $\left(\mathrm{MCHC}_{\text {start }}\right)$ by $9.5 \%, 7.3 \%$ and $5.8 \%$ in 24 hours after admission to the operation room, and by $8.7 \%, 7.6 \%$ and $6.4 \%$ - in the 3th day. On the 14 th day it was characteristic to restore the indicators of $\mathrm{MCHC}$ almost to baseline in all groups.

There is a less deep fall and faster recovery of MCHC numbers in the FDP group compared to the control and CP groups, despite the lack of significant differences between the groups at all control points. The administration of the proposed therapy with the use of D-fructose-1.6-diphosphate sodium salt of hydrate has a positive pharmacologic effect relative to the state of MCHC in the blood of the patients with TD. This is based on the fact that patients in the FDP group differed in the appointment of an additional substance to the main treatment protocol.

In addition, the analysis of the dynamics of RDW in the blood of patients showed the absence of any significant differences between Control, CP and FDP groups. However, it is noteworthy that 24 hours after admission to the operative the RDW levels in the blood were $17.6 \pm 1.8 \%$, $16.7 \pm 1.5 \%$ and $14.7 \pm 1.2 \%$, which were $34.5 \%, 27.5 \%$ and $12.2 \%$ higher than the starting level $\left(\mathrm{RDW}_{\text {start }}\right)$ in patients of Control, CP and FDP groups. So, that means this indicator significantly $(\mathrm{p}>0.05)$ has not been changing in the acute period of TD only in group FDP. On the 3rd day of observation RDW figures were increased by $23.7 \%, 15.3 \%$ and $7.6 \%$ in Control, CP and FDP groups. The tendency to normalization of this indicator has persisted both on the 5th day and on the 15th day (Table 1).

RDW characterizes the degree of anisocytosis, i.e. fluctuations in the volume (size) of $\mathrm{RBCs}$, indicates the presence of a heterogeneous population of cells [12].

The value of the RDW index more than $14.5 \%$ could be considered an indicator of tissue hypoxia [15]. So in our study, the increase in the value of the RDW index may be result of tissue hypoxia and blood transfusions $[12,16]$.

Isik $\mathrm{T}$ et al. have shown RDW levels as an independent correlate predictor index of adverse outcomes also associated with both presence and severity of isolated ischemia than baseline RDW levels measured at ischemic patients and controls [17].

Bujak K et al. noted the negative prognostic effects of elevated RDW levels may be attributed to the adverse effects of independent risk factors such as inflammation, oxidative stress, and vitamin $\mathrm{D}_{3}$ and iron deficiency on bone marrow function (erythropoiesis). Elevated RDW values may reflect the intensity of these phenomena and their unfavourable impacts on bone marrow erythropoiesis. Furthermore, decreased red blood cell deformability among patients with higher RDW values impairs blood flow through the microcirculation, resulting in the diminution of oxygen supply at the tissue level [18].

The FDP group showed a faster recovery of the RDW indicator, despite the absence of statistically significant differences between the groups at all control points. The administration of the proposed therapy with the use of D-fructose-1.6-diphosphate sodium salt of hydrate has a positive effect on the state of extensibility of erythrocyte membranes, their elasticity and hemolytic stability.

Previous studies on this topic demonstrated the notion that increased RDW and decreased RBC, MCHC, MCV, hemoglobin, hematocrit were significantly associated with hospital mortality $[19,20]$.

In summary, in this study, we demonstrated variations in the morphologic properties of RBCs in the acute and early period of TD, as confirmed by pathological changes of the erythrocyte indices. The important thing is that all of patients were comparable by severity of trauma and condition at the time of admission, but differed in treatment protocol. So, the changes in the laboratory parameters are objective indexes of the presence of significant differences in patients of compared groups. The optimized therapy used in the treatment of patients in group III, has a positive effect on the parameters of RBCs, contributes to a better recovery of RBCs after hypoxia resulting multiple trauma.

Study limitations. The study was not conducted in case of identified comorbidities, and in case of patients refuse to participate in the study.

Perspective of further research of this problem are presented in the further study of relationship morphologic changes of RBCs and indicators of cellular metabolism. 


\section{Conclusion}

This study confirms that for multiply injured patients morphological changes of RBCs are characteristic, manifested by changes in erythrocyte indices (MCV, MCH, MCHC, RDW). The course of acute and early periods TD has accompanied variability morphological forms of red blood cells, as evidenced by a decrease in MCV and RDW increased levels of the 3rd to 5th day.

The administration of the proposed therapy with the use of D-fructose-1.6-diphosphate sodium salt of hydrate has a positive effect on the parameters of RBCs, especially contributes to a better recovery of MCV, RDW indices after hypoxia resulting multiple trauma.

Given this, the calculations of the red blood cell indices may carry additional diagnostic information, which allows identify trends for not obvious pathological changes and quality of treatment.

\section{Conflict of interests}

The authors declare that they have no conflicts of interest.

\section{References}

[1] Tosounidis, T., Giannoudis, P. V.; Pape, H. C., Sanders, R., Borrelli, Jr. J. (Eds.) (2016). Pathophysiology of Polytrauma. The Poly-Traumatized Patient with Fractures. Berlin, Heidelberg: Springer, 41-54. doi: http://doi.org/10.1007/978-3-662-47212-5_5

[2] Sauaia, A., Moore, F. A., Moore, E. E. (2017). Postinjury Inflammation and Organ Dysfunction. Critical Care Clinics, 33 (1), 167-191. doi: http://doi.org/10.1016/j.ccc.2016.08.006

[3] Kong, T., Park, J. E., Park, Y. S., Lee, H. S., You, J. S., Chung, H. S. et. al. (2017). Usefulness of serial measurement of the red blood cell distribution width to predict 28-day mortality in patients with trauma. The American Journal of Emergency Medicine, 35 (12), 1819-1827. doi: http://doi.org/10.1016/j.ajem.2017.06.008

[4] Perepelitsa, S. A., Sergunova, V. A., Gudkova, O. E. (2017). The Effect of Perinatal Hypoxia on Red Blood Cell Morphology in Newborns. General Reanimatology, 13 (2), 14-23. doi: http://doi.org/10.15360/1813-9779-2017-2-14-23

[5] Deryugina, A. V., Boyarinov, G. A., Simutis, I. S., Boyarinova, L. V., Azov, N. A. (2018). Morphological and Metabolic Parameters of Red Blood Cells after Their Treatment with Ozone. General Reanimatology, 14 (1), 40-49. doi: http://doi.org/ 10.15360/1813-9779-2018-1-40-49

[6] Bane, B. J.; Rukavitsyn, O. A. (Ed.) (2010). Hematologist Handbook. A-Z. Moscow: BINOM, Laboratory of Knowledge.

[7] Cluitmans, J. C. A. (2016). Red blood cell homeostasis. Molecular mechanisms regulating morphology and function. Radboud University Nijmegen, 189. Available at: https://repository.ubn.ru.nl/handle/2066/157750

[8] Chumakova, S. P., Urazova, O. I., Zima, A. P., Novitskiy, V. V. (2018). Features of the physiology of erythrocytes. Hemolysis and eryptosis. Russian journal of hematology and transfusiology, 63 (4), 343-351. doi: http://doi.org/10.25837/HAT.2019.51.80.003

[9] Grygorczyk, R., Orlov, S. N. (2017). Effects of Hypoxia on Erythrocyte Membrane Properties - Implications for Intravascular Hemolysis and Purinergic Control of Blood Flow. Frontiers in Physiology, 8. doi: http://doi.org/10.3389/fphys.2017.01110

[10] Lugovskaya, S. A., Morozova, V. T., Pochtar, M. E., Dolgov, V. V. (2006). Laboratory hematology. Moscow-Tver: Triada, 224.

[11] Sikora, J., Orlov, S. N., Furuya, K., Grygorczyk, R. (2014). Hemolysis is a primary ATP-release mechanism in human erythrocytes. Blood, 124 (13), 2150-2157. doi: http://doi.org/10.1182/blood-2014-05-572024

[12] Tsompos, C., Panoulis, C., Toutouzas, K., Triantafyllou, A., Zografos, G. Papalois, A. (2016). The Acute Effect of Erythropoietin on Red Blood Cell Distribution Width Levels during Hypoxia-Reoxygenation Injury in Rats. Journal of Analytical \& Pharmaceutical Research, 2 (2). doi: http://doi.org/10.15406/japlr.2016.02.00014

[13] Taruno, A. (2018). ATP Release Channels. International Journal of Molecular Sciences, 19 (3), 808. doi: http://doi.org/10.3390/ ijms 19030808

[14] Tsompos, C., Panoulis, C., Toutouzas, K., Triantafyllou, A., Zografos, G., Papalois, A. (2016). The acute effect of erythropoietin on mean corpuscular volume levels during hypoxia-reoxygenation injury in rats. Journal of Cellular Biotechnology, 2 (1), 77-83. doi: http://doi.org/10.3233/jcb-15028

[15] Egorova, E. N., Pustovalova, R. A., Gorshkova, M. A. (2014). RDW as a marker of the hypoxic state of tissues. Clinical laboratory diagnostics, 9, 59 .

[16] Yčas, J. W., Horrow, J. C., Horne, B. D. (2015). Persistent increase in red cell size distribution width after acute diseases: A biomarker of hypoxemia? Clinica Chimica Acta, 448, 107-117. doi: http://doi.org/10.1016/j.cca.2015.05.021

[17] Isik, T., Kurt, M., Ayhan, E., Uyarel, H., Tanboga, I. H., Korkmaz, A. F. et. al. (2012). Relation of Red Cell Distribution Width With Presence and Severity of Coronary Artery Ectasia. Clinical and Applied Thrombosis/Hemostasis, 18 (5), $441-447$. doi: http://doi.org/10.1177/1076029612447678 
[18] Bujak, K., Wasilewski, J., Osadnik, T., Jonczyk, S., Kołodziejska, A., Gierlotka, M., Gąsior, M. (2015). The Prognostic Role of Red Blood Cell Distribution Width in Coronary Artery Disease: A Review of the Pathophysiology. Disease Markers, 2015, 1-12. doi: http://doi.org/10.1155/2015/824624

[19] Huang, Y.-L., Hu, Z.-D. (2016). Lower mean corpuscular hemoglobin concentration is associated with poorer outcomes in intensive care unit admitted patients with acute myocardial infarction. Annals of Translational Medicine, 4 (10), $190-190$. doi: http://doi.org/10.21037/atm.2016.03.42

[20] Turcato, G., Serafini, V., Dilda, A., Bovo, C., Caruso, B., Ricci, G., Lippi, G. (2016). Red blood cell distribution width independently predicts medium-term mortality and major adverse cardiac events after an acute coronary syndrome. Annals of Translational Medicine, 4 (13), 254. doi: http://doi.org/10.21037/atm.2016.06.35

\title{
BASIC FIBROBLAST GROWTH FACTOR AND ADIPONECTIN IN ADOLESCENCE WITH JUVENILE IDIOPATHIC ARTHRITIS TREATED WITH METHOTREXATE
}

\author{
Liudmyla Parkhomenko ${ }^{1}$ \\ parkhomenko.lk@gmail.com \\ Larysa Strashok ${ }^{1}$ \\ laspediatr1984@gmail.com \\ Olga Pavlova ${ }^{1}$ \\ ospavlova@mail.ua \\ ${ }^{1}$ Department Adolescence medicine \\ Kharkiv Medical academy of postgraduate education \\ 58 Amosova str., Kharkiv, Ukraine, 61176
}

\begin{abstract}
Methotrexate has been applied clinically for juvenile idiopathic arthritis (JIA) treatment for decades. It is recommended for use globally, according all modern guidelines. Despite the fact that fibrosis molecular mechanisms as well as methotrexate (MTX) elimination and fibrosis indexes were studied a lot there is still not enough information for adolescence. Adiponectin, fibroblast growth factor and fibrosis indexes in adolescents with JIA treated with methotrexate were studied in this work.

The aim was to study dynamics of molecular-cellular mechanisms activation of fibrotic processes development in the liver in adolescents with juvenile idiopathic arthritis treated with methotrexate.

Materials and methods: A total of 68 children with juvenile idiopathic arthritis, were enrolled in the study. 25 boys $(36.8 \%)$ and 43 girls $(63.2 \%)$ were examined. Children were divided into three groups in accordance with the methotrexate dose. The following data were analyzed: ESR ( $\mathrm{mm} /$ hour), C-reactive protein (mg/l), Hemolytic activity (CU), circulating immune complexes, (g/l), ALT (U/l), AST (U/l), Adiponectin (mcg/ml), BFGF (pg/ml), APRI index, FIB-4 Score.

Results: According to our results when patients start using MTX they have significantly positive effect. Therefore, when analyzing all parameters liver pathologies may occur before MTX use. When MTX used, its proinflammation and antifibrotic effects lead to normalization of all organs and systems, as well as joints and liver. Also, long-term MTX use can lead to adverse effects.

Conclusions: So, it is important to control possible liver disorders in adolescence treated with MTX. According to our study results we find out that there are decreasing of liver damage parameters in patients which started using MTX.

Keywords: Juvenile idiopathic arthritis, methotrexate, basic fibroblast growth factor, adiponectin.
\end{abstract}

